\title{
Progress Toward Regional Measles Elimination — Worldwide, 2000-2015
}

\author{
Minal K. Patel, MD ${ }^{1}$; Marta Gacic-Dobo, MSc ${ }^{1}$; Peter M. Strebel, MBChB ${ }^{1}$; Alya Dabbagh, PhD ${ }^{1}$; Mick N. Mulders, PhD ${ }^{1}$; \\ Jean-Marie Okwo-Bele, $\mathrm{MD}^{1}$; Laure Dumolard, $\mathrm{PhD}^{1}$; Paul A. Rota, $\mathrm{PhD}^{2}$; Katrina Kretsinger, $\mathrm{MD}^{1}$; James L. Goodson, MPH
}

Adopted in 2000, United Nations Millennium Development Goal 4 set a target to reduce child mortality by two thirds by 2015, with measles vaccination coverage as one of the progress indicators. In 2010, the World Health Assembly (WHA) set three milestones for measles control by 2015: 1) increase routine coverage with the first dose of measles-containing vaccine (MCV1) for children aged 1 year to $\geq 90 \%$ nationally and $\geq 80 \%$ in every district; 2) reduce global annual measles incidence to $<5$ cases per 1 million population; and 3) reduce global measles mortality by $95 \%$ from the 2000 estimate $(1,2) .^{*}$ In 2012, WHA endorsed the Global Vaccine Action Plan ${ }^{\dagger}$ with the objective to eliminate measles in four World Health Organization (WHO) regions by 2015. Countries in all six WHO regions have adopted measles elimination goals. Measles elimination is the absence of endemic measles transmission in a region or other defined geographical area for $\geq 12$ months in the presence of a well performing surveillance system. This report updates a previous report (3) and describes progress toward global measles control milestones and regional measles elimination goals during 2000-2015. During this period, annual reported measles incidence decreased $75 \%$, from 146 to 36 cases per 1 million persons, and annual estimated measles deaths decreased $79 \%$, from 651,600 to 134,200 . However, none of the 2015 milestones or elimination goals were met. Countries and their partners need to act urgently to secure political commitment, raise the visibility of measles, increase vaccination coverage, strengthen surveillance, and mitigate the threat of decreasing resources for immunization once polio eradication is achieved.

\section{Immunization Activities}

To estimate coverage with MCV1 and the second dose of measles-containing vaccine (MCV2) through routine immunization services, $\$$ WHO and the United Nations Children’s

\footnotetext{
*The coverage milestone is to be met by every country, whereas the incidence and mortality reduction milestones are to be met globally.

$\dagger$ The Global Vaccine Action Plan is the implementation plan of the Decade of Vaccines, a collaboration between WHO, UNICEF, the Bill and Melinda Gates Foundation, the National Institute of Allergy and Infectious Diseases, the African Leaders Malaria Alliance, Gavi, the Vaccine Alliance, and others to extend the full benefit of immunization to all persons by 2020 and beyond. In addition to 2015 targets, it also set a target for measles and rubella elimination in five of the six WHO regions by 2020. http://www.who.int/immunization/global_vaccine_action_plan/ en and http://apps.who.int/gb/ebwha/pdf_files/wha65/a65_22-en.pdf.

${ }^{\$}$ For MCV1, among children aged 1 year or, if MCV1 is given at age $\geq 1$ year, among children aged 24 months. For MCV2, among children at the recommended age of administration of MCV2, per the national immunization schedule. WHO/ UNICEF estimates of national immunization coverage are available at http:// www.who.int/immunization/monitoring_surveillance/data/en.
}

Fund (UNICEF) use data from administrative records and surveys reported annually by 194 countries. During 2000-2015, estimated MCV1 coverage increased globally from $72 \%$ to $85 \%$, although coverage has not increased since 2009. The number of countries with $\geq 90 \%$ MCV1 coverage increased from $84(44 \%)$ in 2000 to $129(66 \%)$ in 2012 , but then declined to $119(61 \%)$ in 2015. Since 2003, countries also have reported the number of districts with $\geq 80 \% \mathrm{MCV} 1$ coverage. Among countries with $\geq 90 \% \mathrm{MCV} 1$ coverage nationally, the percentage with $\geq 80 \% \mathrm{MCV} 1$ coverage reported in all districts increased from $2 \%$ of countries (one of 43 ) in 2003 to $44 \%$ (57 of 129) in 2012 and then declined to 39\% (47 of 119) in 2015. Among the estimated 20.8 million infants who did not receive MCV1 through routine immunization services in 2015, approximately 11 million (53\%) were in six countries: India (3.2 million), Nigeria (3 million), Pakistan ( 2 million), Indonesia (1.5 million), Ethiopia (0.7 million), and the Democratic Republic of the Congo (0.6 million).

During 2000-2015, the number of countries providing MCV2 nationally through routine immunization services increased from $97(51 \%)$ to 160 (82\%), with six countries (Angola, Malawi, Mozambique, Nepal, Sierra Leone, and Zimbabwe) introducing MCV2 in 2015. Estimated global MCV2 coverage increased from $15 \%$ in 2000 to $61 \%$ in 2015. During 2015, approximately 184 million persons received MCV during mass immunization campaigns known as supplementary immunization activities (SIAs) implemented in 41 countries, with $32(78 \%)$ providing one or more additional child health interventions during the SIA (Table 1). Based on doses administered, SIA coverage was $\geq 95 \%$ in 21 (51\%) countries; however, among the four countries conducting postSIA coverage surveys, only one estimated coverage at $\geq 95 \%$.

\footnotetext{
Supplemental immunization activities (SIAs) generally are carried out using two target age ranges. An initial, nationwide catch-up SIA focuses on all children aged 9 months -14 years, with the goal of eliminating susceptibility to measles in the general population. Periodic follow-up SIAs then focus on all children born since the last SIA. Follow-up SIAs generally are conducted nationwide every 2-4 years and focus on children aged 9-59 months; their goal is to eliminate any measles susceptibility that has developed in recent birth cohorts and to protect children who did not respond to MCV1.
} 


\section{Disease Incidence}

Countries report the number of measles cases ${ }^{* *}, \dagger \dagger$ from either case-based ${ }^{\S \S}$ or aggregate surveillance systems to WHO and UNICEF annually. In 2015, 189 (97\%) 99 countries conducted case-based surveillance in at least part of the country, and 191 $(98 \%)^{* * *}$ had access to standardized quality-controlled testing through the WHO Global Measles and Rubella Laboratory Network. However, surveillance is weak in many countries, and $43 \%$ did not achieve the sensitivity indicator of reporting $\geq 2$ discarded measles ${ }^{\dagger \dagger \dagger}$ cases per 100,000 population

During 2000-2015, the number of measles cases reported annually worldwide decreased $70 \%$, from 853,479 to 254,928 , and measles incidence decreased $75 \%$, from 146 to 36 cases per 1 million population (Table 2). During 2013-2015, incidence declined from 40 to 36 per 1 million, although fewer countries reported case data in 2015 (169) than did in 2013 (176). . \$S\$ The percentage of reporting countries with an incidence of $<5$ cases per 1 million increased from 38\% (64 of 169) in 2000

** http://apps.who.int/immunization_monitoring/globalsummary/timeseries/ tsincidencemeasles.html.

i† Measles cases are defined differently in different countries. Some countries define measles cases as those that are laboratory-confirmed or epidemiologically confirmed; others define measles cases as those that are laboratory-confirmed, epidemiologically confirmed, or clinically compatible. Laboratory-confirmed cases are suspected measles cases with specimens with detectable measles virus-specific immunoglobulin class $\mathrm{M}$ (IgM) antibodies, or specimens from which measles virus can be isolated or measles virus genome can be detected in appropriate clinical specimens by a proficient laboratory. Epidemiologically linked confirmed measles cases are suspected measles cases that have not been confirmed by a laboratory but are geographically and temporally related to a laboratory-confirmed case or, in the event of a chain of transmission, to another epidemiologically confirmed measles case, with dates of rash onset between cases occurring 7-21 days apart. Clinically compatible measles cases are suspected measles cases with fever and maculopapular rash and cough, coryza, or conjunctivitis, for which no adequate clinical specimen was collected and which have not been linked epidemiologically to a laboratoryconfirmed case of measles or to a laboratory-confirmed case of another communicable disease.

$\$ \$$ A case-based surveillance system is defined as one that collects information about each case at the individual level; in the case of measles, effective casebased surveillance includes confirmatory laboratory testing.

99 Countries without case-based measles surveillance in 2015 were Mauritius, Sao Tome and Principe, Seychelles, and Somalia.

*** Countries without access to standardized quality-controlled testing by the WHO Measles and Rubella Laboratory Network in 2015 were Cape Verde, Sao Tome and Principe, and Seychelles.

$\dagger \dagger$ A discarded case is defined as a suspected case that has been investigated and discarded as nonmeasles using 1) laboratory testing in a proficient laboratory or 2) epidemiological linkage to a laboratory-confirmed outbreak of a communicable disease that is not measles. The discarded case rate is used to measure the sensitivity of measles surveillance.

\$S\$ Countries not reporting in 2013 were Cuba (AMR); Bahrain, Libya, and the United Arab Emirates (EMR); Austria, Bosnia and Herzegovina, Italy, Malta, Monaco, San Marino, and Ukraine (EUR); and Brunei Darussalam, Cook Islands, Fiji, the Marshall Islands, Nauru, Samoa, and Tuvalu (WPR). In 2015, member states not reporting were Mauritius (AFR); El Salvador and the United States of America (AMR); Libya (EMR); Albania, Andorra, Finland, Greece, Monaco, Montenegro, Netherlands, Poland, Portugal, and San Marino (EUR); Indonesia (SEAR); and Cook Islands, Fiji, Kiribati, Marshall Islands, Nauru, Niue, Samoa, Singapore, Tonga, and Tuvalu (WPR). Delays in reporting could affect 2015 data.
TABLE 1. Measles supplementary immunization activities $(\mathrm{SIAs})^{*}$ and the delivery of other child health interventions, by World Health Organization (WHO) region and country - worldwide, 2015

\begin{tabular}{|c|c|c|c|c|c|c|}
\hline \multirow{2}{*}{$\begin{array}{l}\text { WHO region/ } \\
\text { Country }\end{array}$} & \multirow{2}{*}{$\begin{array}{l}\text { Age } \\
\text { group } \\
\text { targeted }\end{array}$} & \multirow{2}{*}{$\begin{array}{l}\text { Extent } \\
\text { of SIA }\end{array}$} & \multicolumn{2}{|c|}{$\begin{array}{l}\text { Children reached in } \\
\text { targeted age group }\end{array}$} & \multirow{2}{*}{$\begin{array}{l}\text { Coverage } \\
\text { survey } \\
\text { results (\%) }\end{array}$} & \multirow{2}{*}{$\begin{array}{c}\text { Other } \\
\text { interventions } \\
\text { delivered }\end{array}$} \\
\hline & & & No. & $(\%)^{\dagger}$ & & \\
\hline \multicolumn{7}{|l|}{ African } \\
\hline Benin & $9 m-9 y$ & $\mathrm{~N}$ & 408,511 & 102 & & \\
\hline Burundi & $18-23 \mathrm{~m}$ & $\mathrm{~N}$ & 22,650 & 8 & & $\begin{array}{l}\text { Vitamin A, } \\
\text { deworming, } \\
\text { micronutrient } \\
\text { supplementation }\end{array}$ \\
\hline Cameroon & $9 m-14 y$ & $\mathrm{~N}$ & $9,229,739$ & 98 & & Rubella vaccine \\
\hline Eritrea & $9-59 m$ & $\mathrm{~N}$ & 350,765 & 80 & & \\
\hline Guinea-Bissau & $9-59 \mathrm{~m}$ & $\mathrm{~N}$ & 223,673 & 86 & & $\begin{array}{l}\text { Vitamin A, } \\
\text { deworming }\end{array}$ \\
\hline Liberia & $9-59 \mathrm{~m}$ & $\mathrm{~N}$ & 596,545 & 99 & & OPV, deworming \\
\hline Malawi & $9-59 \mathrm{~m}$ & SN & 453,202 & 104 & & $\begin{array}{l}\text { Vitamin A, } \\
\text { deworming }\end{array}$ \\
\hline Mali & $9 m-14 y$ & $\mathrm{~N}$ & $9,327,708$ & 112 & & \\
\hline Niger & $9-59 \mathrm{~m}$ & $\mathrm{~N}$ & $3,299,923$ & 96 & & \\
\hline $\begin{array}{l}\text { Nigeria } \\
(2015-2016)^{\S}\end{array}$ & $6 m-10 y$ & SN & $24,069,024$ & 100 & 84 & \\
\hline Sierra Leone & $9-59 \mathrm{~m}$ & $\mathrm{~N}$ & $1,205,865$ & 97 & 69 & OPV \\
\hline South Sudan & $6 m-15 y$ & SN & 690,951 & 51 & & Vitamin A \\
\hline South Sudan & 6-59m & SN & 12,169 & 119 & & Vitamin A \\
\hline Togo & $9 m-9 y$ & SN & 820,335 & 99 & & \\
\hline Uganda & 6-59m & $\mathrm{N}$ & $6,349,182$ & 95 & & OPV \\
\hline Zimbabwe & $9 m-14 y$ & $\mathrm{~N}$ & $5,337,029$ & 103 & & $\begin{array}{l}\text { Rubella vaccine, } \\
\text { Vitamin A }\end{array}$ \\
\hline \multicolumn{7}{|l|}{ Americas } \\
\hline Chile & $1-5 y$ & $\mathrm{~N}$ & $1,023,997$ & 83 & & Rubella vaccine \\
\hline $\begin{array}{l}\text { Dominican } \\
\text { Republic }\end{array}$ & $1-4 y$ & $\mathrm{~N}$ & 742,792 & 95 & & Rubella vaccine \\
\hline \multicolumn{7}{|c|}{ Eastern Mediterranean } \\
\hline Afghanistan & 9-59 m & $\mathrm{N}$ & $6,191,955$ & 113 & 92 & OPV \\
\hline Djibouti & $9 m-25 y$ & $\mathrm{~N}$ & 446,612 & 85 & & OPV \\
\hline Egypt & $9 m-10 y$ & $\mathrm{~N}$ & $23,356,156$ & 102 & & Rubella vaccine \\
\hline Iran & $9 m-15 y$ & SN & $1,804,000$ & 99 & & Rubella vaccine \\
\hline Iraq & $9 m-5 y$ & $\mathrm{~N}$ & $4,461,653$ & 94 & & Rubella vaccine \\
\hline Pakistan & $6 m-10 y$ & SN & $36,511,184$ & 103 & & \\
\hline Saudi Arabia & $6-18 y$ & $\mathrm{~N}$ & \multicolumn{2}{|c|}{ Unknown Unknown } & & $\begin{array}{l}\text { Mumps and } \\
\text { Rubella vaccine }\end{array}$ \\
\hline Somalia & $9 m-9 y$ & SN & $3,518,358$ & 91 & & Vitamin A \\
\hline Syria & $6-59 m$ & $\mathrm{~N}$ & $1,619,630$ & 61 & & $\begin{array}{l}\text { Mumps and } \\
\text { Rubella vaccine, } \\
\text { Vitamin A, Other } \\
\text { routine vaccines } \\
\text { if missing }\end{array}$ \\
\hline $\begin{array}{l}\text { United Arab } \\
\text { Emirates }\end{array}$ & $1-18 y$ & $\mathrm{~N}$ & 915,480 & 69 & & $\begin{array}{l}\text { Mumps and } \\
\text { Rubella vaccine }\end{array}$ \\
\hline Yemen & $6 m-15 y$ & SN & $1,590,462$ & 85 & & $\begin{array}{l}\text { Rubella vaccine, } \\
\text { OPV }\end{array}$ \\
\hline \multicolumn{7}{|l|}{ European } \\
\hline Azerbaijan & Adults & $\mathrm{N}$ & \multicolumn{2}{|c|}{ 10,642 Unknown } & & Rubella vaccine \\
\hline Georgia & $2-30 y$ & $\mathrm{~N}$ & 23,417 & 13 & & $\begin{array}{l}\text { Mumps and } \\
\text { Rubella vaccine }\end{array}$ \\
\hline Kazakhstan & $15-19 y$ & $\mathrm{~N}$ & 851,484 & 97 & & \\
\hline \multicolumn{7}{|l|}{ South-East Asia } \\
\hline India & $9 m-15 y$ & SN & \multicolumn{2}{|c|}{ 890,070 Unknown } & & \\
\hline Myanmar & $9 m-14 y$ & $\mathrm{~N}$ & $13,160,764$ & 94 & & Rubella vaccine \\
\hline Nepal & $6 m-5 y$ & SN & 453,665 & 91 & & $\begin{array}{l}\text { Rubella vaccine, } \\
\text { OPV }\end{array}$ \\
\hline Thailand & $30 m-7 y$ & $\mathrm{~N}$ & $2,244,906$ & 88 & & Rubella vaccine \\
\hline Timor-Leste & $6 m-15 y$ & $\mathrm{~N}$ & 484,850 & 97 & 95 & $\begin{array}{l}\text { Rubella vaccine, } \\
\text { OPV }\end{array}$ \\
\hline
\end{tabular}

See table footnotes on next page. 
TABLE 1. (Continued) Measles supplementary immunization activities (SIAs)* and the delivery of other child health interventions, by World Health Organization (WHO) region and country - worldwide, 2015

\begin{tabular}{|c|c|c|c|c|c|c|}
\hline \multirow{2}{*}{$\begin{array}{l}\text { WHO region/ } \\
\text { Country }\end{array}$} & \multirow{2}{*}{$\begin{array}{c}\text { Age } \\
\text { group } \\
\text { targeted }\end{array}$} & \multirow{2}{*}{$\begin{array}{l}\text { Extent } \\
\text { of SIA }\end{array}$} & \multicolumn{2}{|c|}{$\begin{array}{l}\text { Children reached in } \\
\text { targeted age group }\end{array}$} & \multirow{2}{*}{$\begin{array}{c}\text { Coverage } \\
\text { survey } \\
\text { results (\%) }\end{array}$} & \multirow{2}{*}{$\begin{array}{c}\text { Other } \\
\text { interventions } \\
\text { delivered }\end{array}$} \\
\hline & & & No. & $(\%)^{+}$ & & \\
\hline \multicolumn{7}{|l|}{ Western Pacific } \\
\hline Malaysia & $6 m-16 y$ & SN & 21,518 & 90 & & $\begin{array}{l}\text { Mumps and } \\
\text { Rubella vaccine }\end{array}$ \\
\hline Mongolia & $6 m-6 y$ & $\mathrm{~N}$ & 347,685 & 94 & & Vitamin A \\
\hline $\begin{array}{l}\text { Papua New } \\
\text { Guinea }\end{array}$ & $9 m-14 y$ & SN & 801,436 & 62 & & $\begin{array}{l}\text { Rubella vaccine, } \\
\text { OPV, IPV, } \\
\text { Vitamin A, } \\
\text { deworming }\end{array}$ \\
\hline Vanuatu & $1-15 y$ & $\mathrm{~N}$ & 103,676 & 103 & & $\begin{array}{l}\text { Rubella vaccine, } \\
\text { OPV, Vitamin A, } \\
\text { deworming }\end{array}$ \\
\hline $\begin{array}{l}\text { Vietnam } \\
(2014-2015)^{\S}\end{array}$ & $1-14 y$ & $\mathrm{~N}$ & $19,740,181$ & 98 & & Rubella vaccine \\
\hline Total & & & $183,713,844$ & & & \\
\hline
\end{tabular}

Abbreviations: $I P V=$ inactivated poliovirus vaccine; $\mathrm{m}=$ months; $\mathrm{N}=$ national; $\mathrm{OPV}=$ oral poliovirus vaccine; $\mathrm{SI} A=$ supplementary immunization activity; $\mathrm{SN}=$ subnational; $y=$ years * SIAs generally are carried out using two approaches: 1) An initial, nationwide catch-up SIA targets all children aged 9 months to 14 years; it has the goal of eliminating susceptibility to measles in the general population. Periodic follow-up SIAs then target all children born since the last SIA. 2) Follow-up SIAs are generally conducted nationwide every 2-4 years and generally target children aged 9-59 months; their goal is to eliminate any measles susceptibility that has developed in recent birth cohorts and to protect children who did not respond to the first measles vaccination. The exact age range for follow-up SIAs depends on the age-specific incidence of measles, coverage with 1 dose of measles-containing vaccine, and the time since the last SIA.

+ Values $>100 \%$ indicate that the intervention reached more persons than the estimated target population.

$\S$ Rollover national campaigns started the previous year or will continue into the next year.

to $58 \%$ (98 of 168) in 2014, and to $65 \%$ (109 of 169) in 2015. During 2000-2015, the Region of the Americas (AMR) maintained measles incidence of $<5$ cases per 1 million.

From 2014 to 2015, the number of reported measles cases increased 33\% in the African Region (AFR), 18\% in the Eastern Mediterranean Region (EMR), and 83\% in the European Region (EUR), primarily because of outbreaks in several countries. There was minimal change in reported cases in the SouthEast Asia Region (SEAR), and reported cases decreased $78 \%$ in AMR, with interruption of outbreaks in Brazil, Canada, and the United States. In the Western Pacific Region (WPR), reported measles cases declined 50\%, with decreases in the three most populous countries in the region: China, the Philippines, and Vietnam (Table 2).

Genotypes of viruses isolated from measles cases were reported by $80(51 \%)$ of the 157 countries that reported measles cases in 2015. Among the 24 recognized measles virus genotypes, 11 were detected during 2005-2008, eight during 2009-2014, and six during 2015, excluding those from vaccine reactions and cases of subacute sclerosing panencephalitis, a fatal progressive neurologic disorder caused by persistent measles infection $\mathbf{9 9 9}$

\footnotetext{
999 Griffin DE. Measles virus and the nervous system. Handb Clin Neurol
} 2014;123:577-90. http://dx.doi.org/10.1016/B978-0-444-53488-0.00027-4.
(4). In 2015, among 8,076 reported measles virus sequences, ${ }^{* * * *}$ 847 (from 48 countries) were genotype B3; 70 (10 countries) were D4; 1,801 (52 countries) were D8; 76 (10 countries) were D9; one was G3; and 5,281 (20 countries) were H1 (Table 1).

\section{Disease and Mortality Estimates}

A previously described model for estimating measles disease and mortality was updated with new measles vaccination coverage data, case data, and United Nations population estimates for all countries during 2000-2015, enabling a new series of disease and mortality estimates $(5,6)$. According to the updated data, the estimated number of measles cases declined from 32,768,300 ( $95 \%$ confidence interval $[\mathrm{CI}]=23,393,300-63,222,700)$ in 2000 to $9,719,600$ (CI $=5,731,800-35,451,000)$ in 2015. During this period, the number of estimated annual measles deaths decreased 79\%, from 651,600 to 134,200 (Table 2). Compared with no measles vaccination, measles vaccination prevented an estimated 20.3 million deaths during 2000-2015 (Figure).

\section{Regional Verification of Measles Elimination}

In September 2016, the AMR regional verification commission declared the region free of endemic measles ( 7 ). The WPR regional verification commission reclassified Mongolia as having reestablished endemic measles virus transmission because of an outbreak that lasted for $>1$ year; thus, five WPR member states have been verified as having eliminated endemic measles (8). In 2015, the EUR regional verification commission verified measles elimination in 21 countries (9).

\section{Discussion}

During 2000-2015, increased coverage worldwide with routine doses of MCV, combined with SIAs, contributed to a $75 \%$ decrease in reported measles incidence and a $79 \%$ reduction in estimated measles mortality. During this period, measles vaccination prevented an estimated 20.3 million deaths. Moreover, the number of countries with measles incidence $<5$ per million has increased, although there is a large amount of underreporting. The decreasing number of circulating measles virus genotypes suggests interruption of some chains of transmission. However, despite progress since 2000 , the 2015 global control milestones and regional measles elimination goals were not achieved and much effort is needed if elimination in five of six regions is to be achieved by 2020 . Countries and immunization partners need to substantially

\footnotetext{
**** Sequences were for the 450 nucleotide carboxy-terminal of the nucleocapsid gene in the measles virus genome. Data (as of September 6, 2016) are available from the Measles Nucleotide Surveillance (MeaNS) database, http://www.who-measles.org/Public/Web_Front/main.php.
} 
TABLE 2. Estimates of coverage with the first and second doses of measles-containing vaccine administered through routine immunization services, reported measles cases and incidence, estimated measles deaths, ${ }^{*}$ and reported measles genotypes, by World Health Organization (WHO) region - worldwide, 2000 and 2015

\begin{tabular}{|c|c|c|c|c|c|c|c|c|c|}
\hline WHO region & $\begin{array}{l}\text { Coverage } \\
\text { with first } \\
\text { dose }(\%)^{\dagger}\end{array}$ & $\begin{array}{c}\text { Countries } \\
\text { with } \\
\geq 90 \% \\
\text { coverage } \\
(\%)\end{array}$ & $\begin{array}{l}\text { Coverage } \\
\text { with } \\
\text { second } \\
\text { dose }(\%)^{\dagger}\end{array}$ & $\begin{array}{c}\text { Reported } \\
\text { cases } \\
(\text { No. })^{\S}\end{array}$ & Incidence ${ }^{\S, q}$ & $\begin{array}{c}\% \text { of } \\
\text { countries } \\
\text { with } \\
\text { incidence } \\
<5 \text { per } 1 \\
\text { million }\end{array}$ & $\begin{array}{l}\text { Reported measles } \\
\text { genotypes }(2015)^{* *}\end{array}$ & $\begin{array}{l}\text { Estimated no. of deaths } \\
\qquad(95 \% \mathrm{Cl})\end{array}$ & $\begin{array}{l}\text { Estimated \% } \\
\text { mortality } \\
\text { reduction } \\
\text { from } 2000 \text { to } \\
2015\end{array}$ \\
\hline \multicolumn{10}{|l|}{ African } \\
\hline 2000 & 53 & 9 & 5 & 520,102 & 837 & 5 & & $414,500(287,600-650,600)$ & \\
\hline 2015 & 74 & 26 & 18 & 98,621 & 100 & 52 & B3 & $61,600(27,600-163,600)$ & 85 \\
\hline \multicolumn{10}{|l|}{ Americas } \\
\hline 2000 & 93 & 63 & 44 & 1,754 & 2.1 & 89 & & NA & \\
\hline 2015 & 94 & 83 & 53 & 423 & 0.6 & 97 & B3, D4, D8, D9, H1 & NA & \\
\hline \multicolumn{10}{|c|}{ Eastern Mediterranean } \\
\hline 2000 & 72 & 57 & 29 & 38,592 & 91 & 17 & & $67,000(39,300-114,300)$ & \\
\hline 2015 & 76 & 57 & 68 & 21,335 & 33 & 40 & B3, D8, D9 & $15,900(8,400-57,500)$ & 76 \\
\hline \multicolumn{10}{|l|}{ European } \\
\hline 2000 & 91 & 58 & 48 & 37,421 & 50 & 45 & & $400(100-1,900)$ & \\
\hline 2015 & 94 & 81 & 89 & 25,947 & 31 & 70 & B3, D4, D8, D9, H1 & $80(4-1,500)$ & 79 \\
\hline \multicolumn{10}{|c|}{ South-East Asia } \\
\hline 2000 & 63 & 27 & 3 & 78,558 & 51 & 0 & & $159,200(117,700-212,700)$ & \\
\hline 2015 & 85 & 46 & 71 & 29,109 & 17 & 45 & B3, D4, D8, D9, G3, H1 & $54,500(37,500-85,000)$ & 66 \\
\hline \multicolumn{10}{|c|}{ South-East Asia (excluding India) } \\
\hline 2000 & 78 & 30 & 9 & 39,723 & 80 & 0 & & $59,200(36,200-91,900)$ & \\
\hline 2015 & 80 & 50 & 78 & 3,621 & 10 & 56 & $\mathrm{~B} 3, \mathrm{D} 4, \mathrm{D} 8, \mathrm{D} 9, \mathrm{G} 3, \mathrm{H} 1$ & $5,300(2,100-19,600)$ & 91 \\
\hline \multicolumn{10}{|l|}{ India } \\
\hline 2000 & 56 & NA & 0 & 38,835 & 36 & 0 & & $100,000(81,500-120,800)$ & \\
\hline 2015 & 87 & NA & 69 & 25,488 & 19 & 0 & D4, D8 & $49,200(35,400-65,500)$ & 51 \\
\hline \multicolumn{10}{|c|}{ Western Pacific } \\
\hline 2000 & 85 & 44 & 2 & 177,052 & 105 & 30 & & $10,600(5,200-55,000)$ & \\
\hline 2015 & 96 & 67 & 93 & 65,176 & 35 & 59 & B3, D4, D8, D9, H1 & $2,100(800-46,000)$ & 80 \\
\hline \multicolumn{10}{|l|}{ Total } \\
\hline 2000 & 72 & 43 & 15 & 853,479 & 146 & 38 & & $651,600(449,900-1,034,500)$ & \\
\hline 2015 & 85 & 61 & 61 & 245,928 & 36 & 65 & & $134,200(74,400-353,600)$ & 79 \\
\hline
\end{tabular}

Abbreviations: $\mathrm{Cl}$ = confidence interval; $\mathrm{NA}=$ not applicable; $\mathrm{WHO}=$ World Health Organization.

* Mortality estimates for 2000 might be different from previous reports. When the model used to generate estimated measles deaths is rerun each year using the new WHO/UNICEF Estimates of National Immunization Coverage (WUENIC) data, as well as updated surveillance data, adjusted results for each year, including the baseline year, are also produced and updated.

† Coverage data:WUENIC. Geneva, World Health Organization, 2015 (as of July 15, 2016). http://www.who.int/immunization/monitoring_surveillance/data/en.

$\S$ Reported case data: measles cases (2015) from World Health Organization, 2015 (as of July 15, 2016); http://apps.who.int/immunization_monitoring/globalsummary/ timeseries/tsincidencemeasles.html. Reported cases are a sizeable underestimate of the actual number of cases, accounting for the inconsistency between reported cases and estimated deaths.

I Cases per 1 million population; population data from United Nations, Department of Economic and Social Affairs, Population Division (2015). Any country not reporting data on measles cases for that year was removed from both the numerator and denominator.

** Data for calendar year 2015, as reported to the Measles Nucleotide Surveillance (MeaNS) database; http://www.who-measles.org/Public/Web_Front/main.php.

increase their commitment for additional financial and human resources to 1) enable public education on the importance of vaccination; 2) strengthen health systems with staff, outreach services, and access to reliable vaccine supply to deliver 2 doses of measles vaccine; 3) improve surveillance; and 4) invest in research and innovations to overcome hurdles to achieving high vaccination coverage.

The 2015 global control milestones and regional measles elimination goals were not met because vaccination coverage gaps persist. Globally, MCV1 coverage has stagnated at $84 \%-85 \%$ since 2009 and MCV2 coverage only reached $61 \%$ in 2015 . SIA quality was inadequate to achieve $\geq 95 \%$ coverage in the majority of countries. Furthermore, the discrepancy between high SIA coverage reported by administrative methods and lower coverage found by a limited number of post-SIA coverage surveys indicates that SIA quality might also be inadequate in countries with high reported administrative coverage. Countries need to allocate more time for early planning and preparation for high-quality immunization campaigns, with careful assessment of pre-SIA readiness, well-conducted intra-campaign and postcampaign monitoring, and proper implementation of appropriately budgeted activities to vaccinate persons missed during the SIA. 
FIGURE. Estimated annual number of measles deaths with vaccination and had there been no vaccination — worldwide, 2000-2015*

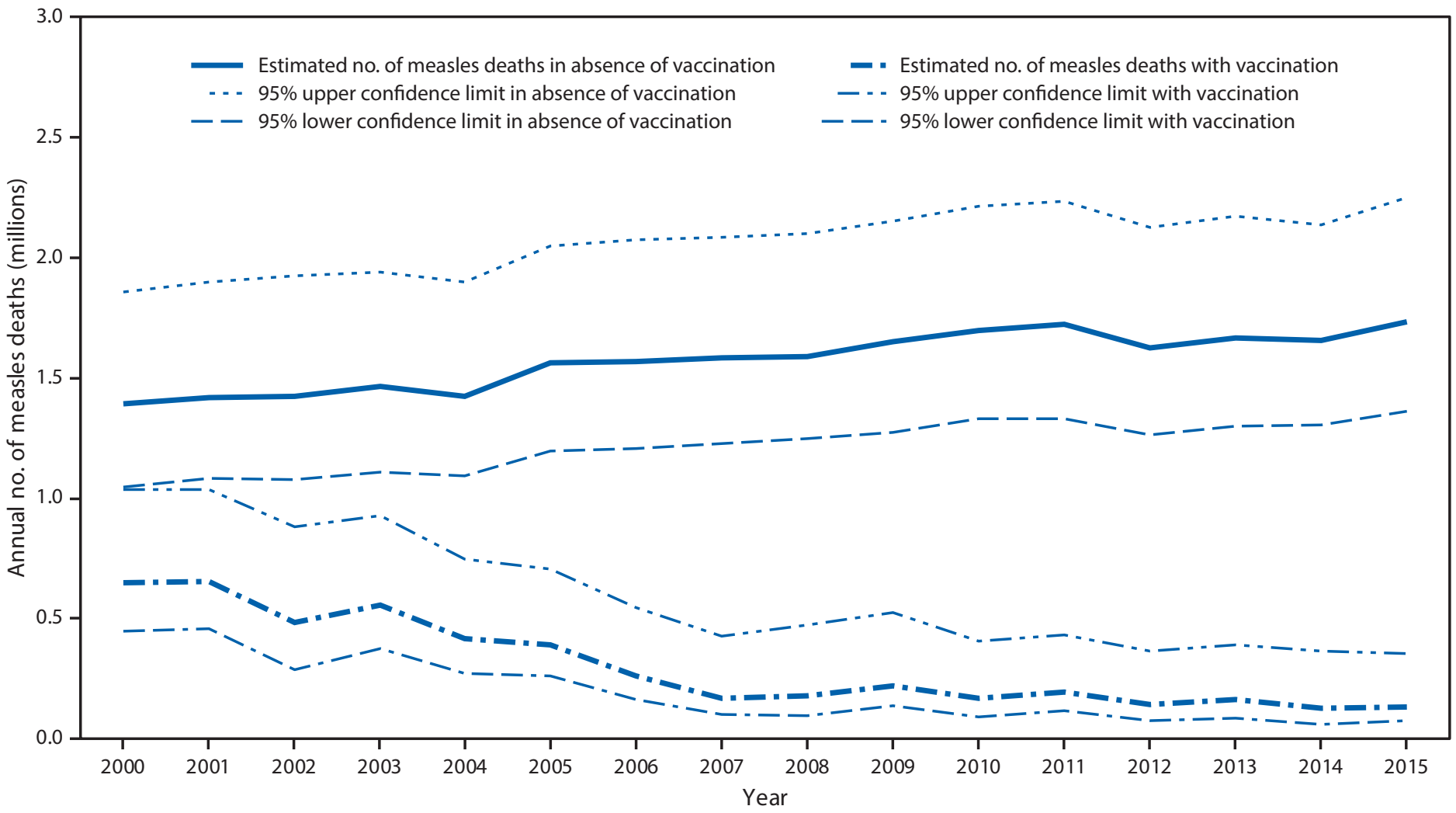

* Compared with no measles vaccination, measles vaccination prevented an estimated cumulative total of 20.3 million deaths during $2000-2015$.

The findings in this report are subject to at least three limitations. First, SIA coverage data might be biased by inaccurate reports of the number of doses delivered, doses administered to children outside the target age group, and inaccurate estimates of the target population size. Second, there are large differences between the estimated and reported incidence, indicating variable surveillance sensitivity, making comparisons difficult; in addition, not all ill persons seek care. Finally, misclassification might occur for reported cases that are not laboratory-confirmed or in countries that report aggregate numbers of unconfirmed cases rather than case-based data for confirmed cases.

The decrease in measles mortality is one of four main contributors (the others are decrease in mortality from diarrhea, malaria, and pneumonia) to the decline in overall child mortality worldwide and progress toward Millennium Development Goal 4, but continued work is needed to help achieve regional elimination (10). Of serious concern is the possibility that the gains made so far and future progress in measles control and elimination could be threatened if polio-funded resources that support routine immunization services, measles SIAs, and measles surveillance activities diminish or disappear following polio eradication. Those countries with the highest measles

\section{Summary}

What is already known about this topic?

During 2000-2010, global vaccination coverage with the first dose of measles-containing vaccine (MCV1) increased from $72 \%$ to $85 \%$, and annual measles incidence decreased from 146 reported cases per 1 million population to 50 cases per 1 million. What is added by this report?

During 2000-2015, an estimated 20.3 million deaths were prevented by measles vaccination, and measles incidence decreased $75 \%$, from 146 to 36 cases per 1 million population. The number of countries providing the second dose of measles-containing vaccine (MCV2) nationally through routine immunization services increased to 160 (82\%) in 2015, and global MCV2 coverage was $61 \%$. In 2015, a total of 184 million persons were vaccinated against measles during supplementary immunization activities. Although measles vaccination has saved millions of lives since 2000 , data indicate that the progress toward elimination goals has slowed since 2010 . What are the implications for public health practice? Reaching measles control and elimination goals will require addressing policy and practice gaps that prevent reaching larger numbers of children with measles vaccination, increasing visibility of measles elimination efforts, assuring funding as polio funding decreases, and ensuring adequate resources for strengthening health systems. 
mortality rely most heavily on polio-funded resources and are at highest risk if these resources are not transitioned to adequately support other parts of the immunization program after polio eradication is achieved. Countries and partners need to act urgently to secure political commitment, raise the visibility of measles, increase vaccination coverage, strengthen surveillance, and mitigate the threat of resources for immunization programs decreasing once polio eradication is achieved.

\footnotetext{
${ }^{1}$ Department of Immunization, Vaccines, and Biologicals, World Health Organization; ${ }^{2}$ Division of Viral Diseases, National Center for Immunization and Respiratory Diseases, CDC; ${ }^{3}$ Global Immunization Division, Center for Global Health, CDC.
}

Corresponding author: Minal Patel, patelm@who.int.

\section{References}

1. United Nations General Assembly. United Nations millennium declaration. New York, NY: United Nations General Assembly; 2000. http://www.un.org/millenniumgoals/

2. World Health Organization. Global eradication of measles: report by the Secretariat. Geneva, Switzerland: World Health Organization; 2010. http://apps.who.int/gb/ebwha/pdf_files/wha63/a63_18-en.pdf
3. Perry RT, Murray JS, Gacic-Dobo M, et al. Progress toward regional measles elimination-worldwide, 2000-2014. MMWR Morb Mortal Wkly Rep 2015;64:1246-51. http://dx.doi.org/10.15585/mmwr.6444a4

4. Genetic diversity of wild-type measles viruses and the global measles nucleotide surveillance database (MeaNS). Wkly Epidemiol Rec 2015;90:373-80.

5. Simons E, Ferrari M, Fricks J, et al. Assessment of the 2010 global measles mortality reduction goal: results from a model of surveillance data. Lancet 2012;379:2173-8. http://dx.doi.org/10.1016/S0140-6736(12)60522-4

6. Chen S, Fricks J, Ferrari MJ. Tracking measles infection through nonlinear state space models. J R Stat Soc Ser C Appl Stat 2012;61:117-34. http://dx.doi.org/10.1111/j.1467-9876.2011.01001.x

7. Pan American Health Organization. Region of the Americas is declared free of measles. Washington, DC: Pan American Health Organization; 2016. http://www.paho.org/hq/index.php?option=com_content\&view $=$ article\&id=12528\&Itemid=1926\&lang=en

8. Regional Office for the Western Pacific. Hong Kong SAR (China) achieves measles-free status. Manila, Philippines: World Health Organization, Regional Office for the Western Pacific; 2016. http:// www.wpro.who.int/mediacentre/releases/2016/20160921/en/

9. Regional Office for Europe. Fourth Meeting of the European Regional Verification Commission for Measles and Rubella Elimination (RVC). Copenhagen, Denmark: World Health Organization, Regional Office for Europe; 2015. http://www.euro.who.int/__data/assets/pdf_ file/0011/304958/4th-RVC-meeting-report.pdf

10. GBD 2015 Child Mortality Collaborators. Global, regional, national, and selected subnational levels of stillbirths, neonatal, infant, and under-5 mortality, 1980-2015: a systematic analysis for the Global Burden of Disease Study 2015. Lancet 2016;388:1725-74. http://dx.doi. org/10.1016/S0140-6736(16)31575-6 